\title{
Kajian Tipologi dan Pemanfaatan Sumber Daya Air di Provinsi Aceh
}

\author{
Ahmad Nubli Gadeng1, Dede Rohmat², Ramli³ , Muhammad Okta Ridha Maulidian", \\ Mirza Desfandi ${ }^{5}$, dan Furqan Ishak Aksa ${ }^{6}$
}

1,4,5 Jurusan Pendidikan Geografi Fakultas Keguruan dan Ilmu Pendidikan Universitas Syiah Kuala; e-mail: ahmadnubli@unsyiah.ac.id

1,2 Jurusan Pendidikan Geografi Sekolah Pascasarjana Universitas Pendidikan Indonesia

3 Program Pascasarjana Universitas Syiah Kuala

${ }^{6}$ Jurusan Pendidikan Geografi Fakultas Keguruan dan Ilmu Pendidikan Universitas Samudra

\begin{abstract}
ABSTRAK
Air merupakan material yang sangat dibutuhkan oleh semua makhluk hidup yang ada di bumi, tanpa apa air kehidupan tidak dapat berlangsung dengan sempurna. Akan tetapi ketersediaan air di setiap daerah berbeda-beda antara satu dengan lainnya. Tujuan dari penelitian ini untuk mengetahui bagaimana tipologi dan pemanfaatan sumber daya air di Aceh. Metodologi yang digunakan yaitu library research (penelitian kepustakaan). Hasil yang didapatkan yaitu, Aceh memiliki berbagai tipologi sumber daya air, Pertama, memiliki 14 CAT (Cekungan Air Tanah), ada yang skala kabupaten/Kota, skala lintas kabupaten/kota bahkan skala lintas provinsi. Kedua, memiliki 10 Sungai, 11 WS (Wilayah Sungai), 15 DAS (Daerah Aliran Sungai) dan 7 Danau. Berbagai sumber daya air tersebut yang dimanfaatkan oleh penduduk Aceh berjumlah 5.189 .466 jiwa, dengan jumlah kepala rumah tangga (kepala keluarga) $1.231 .058 \mathrm{KK}$, dan tingkat kepadatan penduduk $91 \mathrm{Jiwa} \mathrm{Km}^{2}$, sehingga dapat dipastikan dengan sumber daya air yang sangat melimpah, pasokan air yang dibutuhkan oleh masyarakat akan selalu tercukupi. Terlebih lagi dalam hal pemanfaatan air untuk berbagai keperluan masyarakat, seperti MCK (mandi, cuci, kakus), keperluan ibadah, keperluan pertanian, perkebunan, peternakan, perindustrian, dan berbagai keperluan lainnya dalam rangka menunjang kebutuhan hidup masyarakat yang terdapat di Aceh.
\end{abstract}

Kata kunci: Pemanfaatan, Sumber Daya Air, Tipologi

\begin{abstract}
Water is a material that is needed by all living things on earth, without what water life can not take place perfectly, as well as the people of Aceh Province. However, the availability of water in each region varies from one another. The purpose of this study is to find out how the typology and utilization of water resources in Aceh Province. The methodology used is library research. The results obtained are, Aceh Province has various typologies of water resources, First, Aceh has 14 CAT (Groundwater Basin), there is a scale in the district / city, scale across districts / cities and even scale across provinces. Secondly, Aceh has 10 rivers, Aceh has 11 WSs (river areas), Aceh has 15 watersheds (watersheds) and Aceh has 7 lakes. The various water resources utilized by the population in Aceh Province are 5,189,466 people, with the number of household heads (family heads) 1,231,058 households, and the population density level of 91 souls / $\mathrm{km}^{2}$, so that it can be ascertained with water resources that are very abundant, the water supply needed by the people in Aceh Province will always be fulfilled. Moreover, in the case of water utilization in Aceh Province for various community needs, such as MCK (bathing, washing, toilet), worship needs, agricultural needs, plantations, animal husbandry, industry, and various other needs in order to support the community's living needs in the Province Aceh. We hope that the Province of Aceh be freed from a crisis or prolonged water shortage as happened in various other provinces in Indonesia during the dry season.
\end{abstract}

Keywords: Utilization, Water resources, Typology

Citation: Gadeng, A.N., Rohmat, D., Ramli, Maulidian, M.O.R., Desfandi, M., dan Aksa, F.I. (2020). Kajian Tipologi dan Pemanfaatan Sumber Daya Air di Provinsi Aceh. Jurnal Ilmu Lingkungan, 18(2), 333-341, doi:10.14710/jil.18.2.333-341

\section{Pendahuluan}

Air merupakan material yang sangat dibutuhkan oleh semua makhluk hidup yang ada di bumi, tanpa apa air kehidupan tidak dapat berlangsung dengan sempurna, dengan demikian air menjadi kebutuhan primer untuk makhluk hidup. Sumber daya air terdapat di berbagai tempat, akan tetapi ketersediaan air di setiap daerah berbeda-beda antara satu dengan lainnya. Air yang layak dikonsumsi merupakan air yang memenuhi standar kualitas dan kuantitas air baku. Seizarwati dan Rengganis (2016 :77) Dalam rangka penyediaan air baku di suatu daerah, tidak hanya kuantitas tetapi juga 
kualitas memiliki peranan penting dalam menentukan kelayakan air atau pemanfaatan sumber air untuk berbagai penggunaan. Kondisi kualitas air tanah cenderung berubah bergantung pada lingkungan yang dilaluinya serta lamanya air tersebut mengalir di dalam lapisan batuan (Seizarwati dan Rengganis, 2016: 78).

Air tanah dan air permukaan seperti yang terdapat di laut, danau, dan sungai sangat rentan tercemar oleh berbagai faktor, sehingga mempengaruhi akan kualitas dan kuantitas air. Proses yang dapat mempengaruhi perubahan kualitas air tanah sepanjang aliran diantaranya, proses evaporasi, pelarutan mineral, pengendapan, penyerapan, pencampuran, pertukaran ion, dan sebagainya (Younger, 2007). Kemudian, kualitas air sungai dipengaruhi oleh kualitas pasokan air yang berasal dari daerah tangkapan sedangkan kualitas pasokan air dari daerah tangkapan berkaitan dengan aktivitas manusia yang ada di dalamnya (Wiwoho, 2005).

Berbagai aktivitas manusia dalam memenuhi kebutuhan hidupnya yang berasal dari kegiatan industri, rumah tangga, dan pertanian akan menghasilkan limbah yang memberi sumbangan pada penurunan kualitas air sungai (Suriawiria, 2003). Perubahan pola pemanfaatan lahan menjadi lahan pertanian, tegalan dan permukiman serta meningkatnya aktivitas industri akan memberikan dampak terhadap kondisi hidrologis dalam suatu Daerah Aliran Sungai (Agustiningsih, dkk. 2012:64). Oleh karena itu, peran aktif masyarakat dan pemerintah sangat dibutuhkan dalam menjaga dan melindungi akan kualitas dan kuantitas air yang terdapat di permukaan agar tidak tercemar dan keberadaan air selalu tersedia di dalam kehidupan.

Begitu juga halnya dengan masyarakat yang berada di Aceh, membutuhkan air untuk berbagai keperluan seperti kebutuhan rumah tangga, kebutuhan industri dan kebutuhan pertanian dalam rangka memenuhi kebutuhan sehari-hari masyarakat. Provinsi Aceh termasuk ke dalam Indonesia bagian barat, Provinsi Aceh memiliki posisi strategis sebagai pintu gerbang lalu lintas perdagangan Nasional dan Internasional yang menghubungkan belahan dunia timur dan barat. secara geografis Provinsi Aceh berada di ujung barat laut Pulau Sumatera, Provinsi Aceh sebelah utara berbatasan dengan Selat Malaka dan Teluk Benggala, sebelah timur berbatasan dengan Selat Malaka dan Provinsi Sumatera Utara, sebelah selatan berbatasan dengan Provinsi Sumatera Utara dan Samudera Hindia, sebelah barat berbatasan dengan Samudera Hindia.

Secara astronomis, Provinsi Aceh terletak pada $2^{0} 00^{\prime} 00^{\prime \prime}-6^{0} 04^{\prime} 30^{\prime \prime}$ Lintang Utara dan 94058'34"-98015'03" Bujur Timur, dengan ibukota provinsi terletak di Banda Aceh, Provinsi Aceh memiliki luas wilayah 56.758,85 $\mathrm{Km}^{2}$ atau $5.675 .850 \mathrm{Ha}$ dengan kata lain 12,26 persen dari luas Pulau Sumatera, Provinsi Aceh memiliki wilayah lautan sejauh 12 mil seluas 7.479 .802 Ha dengan garis pantai $2.666,27 \mathrm{Km}^{2}$. Secara administratif pada tahun 2009, Provinsi Aceh memiliki 23 kabupaten/kota yang terdiri atas 18 kabupaten dan 5 kota, 276 kecamatan, 755 mukim dan 6.423 gampong atau desa.

Provinsi Aceh memiliki kondisi topografi mulai dari datar hingga bergunung. Wilayah di Provinsi Aceh yang memiliki kondisi topografi daerah datar sampai landai sekitar 32 persen dari luas wilayah Provinsi Aceh, sedangkan wilayah dengan kondisi topografi berbukit hingga bergunung mencapai sekitar 68 persen dari luas wilayah Provinsi Aceh. Daerah dengan kondisi topografi bergunung terdapat dibagian tengah Provinsi Aceh yang merupakan bagian dari gugusan pegunungan bukit barisan dan daerah dengan kondisi topografi berbukit dan landai terdapat di bagian utara dan timur Provinsi Aceh.

Berdasarkan kondisi kelas topografi wilayah tersebut, Provinsi Aceh memiliki topografi datar (0-2\%) tersebar di sepanjang pantai bagian barat sampai bagian selatan dan pantai bagian utara sampai bagian timur sebesar 24.83 persen dari total wilayah; landai (2-15\%) tersebar di antara wilayah pegunungan Seulawah dengan Sungai Krueng Aceh, di bagian pantai barat sampai selatan dan pantai utara sampai timur sebesar 11,29 persen dari total wilayah; agak curam (15-40\%) sebesar 25,82 persen dan sangat curam (> 40\%) yang merupakan punggung pegunungan Seulawah, gunung Leuser, dan bahu dari sungai-sungai yang ada sebesar 38,06 persen dari total wilayah.

Provinsi Aceh memiliki ketinggian rata-rata 125 meter di atas permukaan laut. Persentase wilayah berdasarkan ketinggiannya yaitu: (1) Daerah berketinggian 0-25 MDPL merupakan 22,62 persen luas wilayah Provinsi Aceh (1,283,877.27 ha), (2) Daerah berketinggian 25-1.000 MDPL sebesar 54,22 persen luas wilayah Provinsi Aceh (3,077,445.87 ha), dan (3) Daerah berketinggian di atas 1.000 MDPL sebesar 23,16 persen luas wilayah Provinsi Aceh (1,314,526.86 ha).

Sehingga secara keseluruhan di dalam kehidupan masyarakat Provinsi Aceh, membagi wilayah ke dalam tiga bagian yaitu, Pertama: Provinsi Aceh Bagian Pantai Timur yang terdiri dari Kota Sabang, Kota Banda Aceh, Kabupaten Aceh Besar, Kabupaten Pidie, Kabupaten Pidie Jaya, Kabupaten Bireun, Kabupaten Aceh Utara, Kota Lhokseumawe, Kabupaten Aceh Timur, Kota Langsa, dan Kabupaten Aceh Tamiang. Kedua: Provinsi Aceh Bagian Pantai Tengah yang terdiri dari Kabupaten Bener Meriah, Kabupaten Aceh Tengah, Kabupaten Gayo Lues dan Kabupaten Aceh Tenggara. Ketiga: Provinsi Aceh Bagian Pantai Barat Selatan yang terdiri dari Kabupaten Aceh Jaya, Kabupaten Aceh Barat, Kabupaten Nagan Raya, Kabupaten Aceh Barat Daya, Kabupaten Aceh Selatan, Kabupaten Singkil, Kota Subulussalam, dan Kabupaten Simeulue.

Dengan dukungan kondisi topografi dan morfologi yang dimiliki Provinsi Aceh sebagaimana yang sudah disebutkan di atas, maka sangat wajar jikalau Provinsi Aceh memiliki berbagai keragaman dalam jenis sumber daya air yang terdapat di wilayah Provinsi Aceh. Sumber daya air yang terdapat di Provinsi Aceh sangat melimpah, mulai dari mata air, sungai, danau dan cekungan air tanah (CAT). Keragaman sumber daya air tersebut dapat dikelompokkan ke dalam tipologi sumber daya air. Dengan dikelompokkannya berbagai jenis-jenis sumber daya air, sehingga masyarakat dapat mengetahui tentang di mana saja keberadaan sumber daya air yang terdapat di Provinsi Aceh, kemudian diharapkan masyarakat dapat menjaga, melindungi dan mengelola dengan baik berbagai sumber daya air tersebut untuk anak cucu di masa yang akan datang.

Oleh karena itu, membuat penulis tertarik untuk mengangkat judul makalah tentang "Kajian Tipologi dan Pemanfaatan Sumber Daya Air Di Provinsi Aceh”. Dengan 
rumusan masalah dalam artikel ini yaitu bagaimanakah kajian tipologi dan pemanfaatan sumber daya air di Provinsi Aceh. Dan adapun tujuan dalam artikel ini yaitu untuk mengetahui dan memperkenalkan kepada masyarakat tentang tipologi dan pemanfaatan sumber daya air di Provinsi Aceh.

\section{Metode}

Metode penelitian yang digunakan dalam penelitian ini yaitu deskriptif dengan pendekatan kualitatif. Teknik pengumpulan data menggunakan studi kepustakaan yang relevan dengan tema yang sedang dibahas, teknik ini dengan menelaah sejumlah literatur yang bersumber dari buku-buku, jurnal ilmiah dan peraturan perundangundangan Republik Indonesia yang relevan dengan materi pembahasan pada artikel ini.

\section{Hasil dan Pembahasan}

Artikel ini akan membahas tentang kajian tipologi dan pemanfaatan sumber daya air yang terdapat di Provinsi Aceh. Tipologi sebagai suatu ilmu yang mempelajari tentang pengelompokan berdasarkan tipe atau jenisnya masing-masing. Di Provinsi Aceh terdapat berbagai jenis sumber daya air yang berada di dalam kehidupan masyarakat Provinsi Aceh, serta berbagai jenis sumber daya air dimanfaatkan dengan baik oleh seluruh masyarakat Aceh.

Sumber daya air yang terdapat di Provinsi Aceh dan dimanfaatkan selama ini oleh masyarakat seperti kebutuhan rumah tangga, industri dan pertanian serta berbagai kebutuhan lainnya dalam rangka menunjang kegiatan sehari-hari. Dapat dikelompokkan menjadi beberapa bagian yaitu, cekungan air tanah (CAT), sungai, wilayah sungai(WS) dan daerah aliran sungai (DAS), serta danau yang terdapat dan tersebar di seluruh wilayah di Provinsi Aceh. Berikut penulis akan menjelaskan berbagai karakteristik sumber daya air tersebut, yaitu:

\section{1) Cekungan Air Tanah (CAT)}

Cekungan air tanah atau yang biasa disingkat dengan CAT merupakan suatu tempat atau wilayah untuk cadangan penyimpanan air yang terdapat di bawah tanah dalam waktu tertentu, biasanya cekungan air tanah memiliki batasan hidrogeologis sesuai dengan daerahnya masing-masing. Dan pemanfaatan CAT juga dilindungi oleh pemerintah, sehingga masyarakat tidak boleh memanfatkan cekungan air tanah dengan bebas, seperti halnya masyarakat dapat memanfaatkan dengan bebas sumber daya air permukaan sungai, danau dan laut.

Berdasarkan UU No. 7 tahun 2004 tentang Sumber Daya Air, daerah aliran air tanah disebut juga dengan CAT atau biasanya dikenal dengan groundwater basin, adapun pengertian CAT yaitu suatu daerah yang dibatasi oleh batasan hidrogeologis, sebagai tempat semua kejadian hidrogeologis seperti pengimbuhan, pengaliran serta pelepasan air tanah terjadi. Dapat dikatakan bahwa CAT adalah batas teknis pengelolaan sumber daya air untuk air tanah (Kodoatie dan Sjarief, 2010:131; Kodoatie, 2012:183)

Kemudian, CAT memiliki pengaruh dengan keadaan geologis dan geomorfologi suatu daerah atau wilayah administratif, sehingga keadaan CAT yang berada di setiap daerah juga berbeda-beda. Cekungan air tanah 335 juga sebagai salah satu contoh dari sistem geomorfologi (Gregory dan Walling, 1973). Kodoatie dan Sjarief (2010:281) CAT berada di daratan dengan pelamparan dapat sampai di bawah dasar laut, akuifer dan akuitard memanjang secara vertikal dan horizontal dengan batas tertentu, batas vertikal suatu akuifer ditentukan oleh kondisi stratigraphy dan geohistoric lapisan, sedangkan batas horizontal dikontrol berdasarkan sedimentary dan geostructural lapisan-lapisan tersebut. Karena unit/bagian hidrostratigrafi dikendalikan oleh kondisi geologi, maka sangat penting mengidentifikasi unit-unit untuk setiap lapisan.

Kodoatie dan Sjarief (2010:282) Secara hidrogeologi, unit terbesar dengan suatu batas tertentu disebut sebagai cekungan air tanah (groundwater basin), yang menunjukkan suatu cekungan deposit (sedimentary basin), cekungan deposit adalah suatu daerah di mana pengendapan telah terjadi secara terus-menerus untuk suatu periode waktu tertentu dan terbentuk dari akumulasi lapisan-lapisan yang tebal, untuk endapan aluvial maka sedimentary basin merupakan sumber yang paling besar dari air tanah.

Boonstra dan Ridder (1981) dalam Jusuf (2015:4) pada cekungan air tanah mengalami proses hidrologi yang berlangsung secara terus menerus, faktor litologi sangat menentukan terhadap kecepatan proses perkolasi air permukaan, keterdapatan endapan aluvial merupakan ciri utama litologi suatu cekungan air tanah. Kemudian, Todd (1980) cekungan air tanah merupakan suatu satuan hidrogeologi yang terdiri dari satu atau beberapa bagian akuifer yang saling berhubungan membentuk suatu sistem dan dapat berubah akibat perubahan lingkungan. Kriteria CAT berdasarkan Peraturan Pemerintah No. 43 tahun 2008 adalah, sebagai berikut:

a) Mempunyai batas hidrogeologis yang dikontrol oleh kondisi geologis dan kondisi hidraulik air tanah. Batas hidrogeologis adalah batas fisik wilayah pengelolaan air tanah. Batas hidrogeologis dapat berupa batas antara batuan lulus dan tidak lulus air, batas pemisah air tanah, dan batas yang terbentuk oleh struktur geologi yang meliputi antara lain, kemiringan lapisan batuan, lipatan dan patahan.

b) Mempunyai daerah imbuhan dan daerah lepasan air tanah dalam satu sistem pembentukan air tanah. Daerah "imbuhan air tanah" merupakan kawasan lindung air tanah, di daerah tersebut air tanah tidak untuk didayagunakan, sedangkan daerah lepasan air tanah secara umum dapat didayagunakan, dapat dikatakan sebagai kawasan budidaya air tanah.

c) Memiliki satu kesatuan sistem akuifer: yaitu kesatuan susunan akuifer, termasuk lapisan batuan kedap air yang berada di dalamnya. Akuifer dapat berada pada kondisi tidak tertekan atau bebas (unconfined) dan tertekan (confined).

Berdasarkan pengertian di atas, cekungan air tanah (groundwater basin) memiliki pengertian yang berbeda dengan cekungan deposit (sedimentary basin). Keberadaan CAT di suatu daerah atau wilayah administratif sangat penting, hal ini dikarenakan cekungan air tanah yang berfungsi sebagai tempat penyimpanan air, sehingga air yang terdapat di daerah CAT tidak dimanfaatkan secara sembarangan oleh masyarakat, dikarenakan pada saat air yang terdapat di 
daerah permukaan habis atau terjadi kekeringan, maka sumber daya air yang tersimpan dalam CAT yang menjadi alternatif air untuk dimanfaatkan oleh masyarakat.

Ada 421 CAT dan ada juga daerah-daerah yang bukan (Non) CAT tidak potensial yang tersebar di seluruh pulau-pulau di Indonesia (Pusat Lingkungan Geologi, 2009). (Kodoatie dan Sjarief, 2010:131; Kodoatie, 2012:183) Luas CAT : $907.615 \mathrm{Km}^{2}$ (atau $47,2 \%$ luas daratan); Luas Non-CAT : $1.014 .985 \mathrm{Km}^{2}$ (atau 52,8\% luas daratan). Di Indonesia terdapat 421 CAT, dan sebagian besar tersebar di pulau-pulau besar dengan potensi air tanah diperkirakan mencapai 517 milyar $\mathrm{m}^{3}$ /tahun. Sebanyak 80 CAT terdapat di Pulau Jawa dan Pulau Madura dengan potensi air tanah yang dimiliki sekitar 41 milyar $\mathrm{m}^{3} /$ tahun. Luas tiap cekungan air tanah tidak sama, tergantung kepada kondisi hidrogeologi setempat. Sangat sedikit ditemui CAT di pulau-pulau kecil seperti Pulau Nusa Tenggara dan Pulau Maluku, akan tetapi CAT yang sangat luas wilayahnya banyak ditemui di pulau-pulau besar seperti Pulau Papua, Pulau Sulawesi, Pulau Kalimantan, Pulau Jawa, dan Pulau Sumatera. cekungan air tanah CAT juga tidak selalu mengikuti daerah aliran sungai di atasnya (Kodoatie dan Sjarief, 2010:131; Kodoatie, 2012:183). CAT yang terdapat di Indonesia terbagi menjadi empat kategori yaitu lintas negara, lintas provinsi, lintas kabupaten/kota bahkan sampai dalam kabupaten/kota. Berikut akan ditampilkan tabel 1 tentang potensi air tanah yang terdapat di CAT Indonesia

Di Provinsi Aceh terdapat 14 CAT, untuk lebih jelasnya dapat dilihat pada gambar 1. Berdasarkan gambar 1 tentang peta CAT yang terdapat di Aceh, maka penulis akan mencoba untuk menjelaskan tentang persebaran CAT yang terdapat di Provinsi Aceh. Pertama: CAT Banda Aceh dengan luas CAT $1470 \mathrm{Km}^{2}$, berada pada lintas kabupaten/kota, CAT ini terdapat dalam tiga kabupaten yaitu Kota Banda Aceh, Kabupaten
Aceh Besar dan Kabupaten Pidie. Kedua: CAT Sigli dengan luas CAT $619 \mathrm{Km}^{2}$ hanya berada dalam Kabupaten Pidie saja, dan tidak terhubung dengan kabupaten lainnya yang berada di sekitar Kabupaten Pidie.

Ketiga: CAT Jeunib berada pada lintas kabupaten/kota, CAT Jeunib dengan luas CAT $310 \mathrm{Km}^{2}$ terdapat dalam Kabupaten Pidie Jaya dan Kabupaten Bireun. Keempat: CAT Kemiki berada pada lintas kabupaten/kota, CAT Kemiki dengan luas CAT $281 \mathrm{Km}^{2}$ terdapat dalam Kabupaten Pidie, Kabupaten Pidie Jaya dan Kabupaten Bireun. Kelima: CAT Meulaboh, berada pada lintas kabupaten/kota, cekungan air tanah (CAT) Meulaboh dengan luas CAT $4500 \mathrm{Km}^{2}$ terdapat pada Kabupaten Aceh Jaya, Kabupaten Aceh Barat, Kabupaten Aceh Barat Daya, dan Kabupaten Nagan Raya.

Keenam: CAT Peudada berada pada lintas kabupaten/kota, cekungan air tanah (CAT) Peudada dengan luas CAT $1198 \mathrm{Km}^{2}$ terdapat dalam kabupaten Bireun, Kabupaten Aceh Utara dan Kabupaten Bener Meriah. Ketujuh, CAT Lhokseumawe berada pada lintas kabupaten/kota, CAT Lhokseumawe dengan luas CAT $2913 \mathrm{Km}^{2}$ terdapat dalam Kabupaten Aceh Utara, Kota Lhokseumawe dan Kabupaten Aceh Timur. Kedelapan: CAT Lampahan, berada pada lintas kabupaten/kota, CAT Lampahan dengan luas CAT $500 \mathrm{Km}^{2}$ terdapat dalam Kabupaten Aceh Tengah dan Kabupaten Bener Meriah.

Kesembilan: CAT Telege, berada pada lintas kabupaten/kota, CAT Telege dengan luas CAT $292 \mathrm{Km}^{2}$ terdapat dalam Kabupaten Aceh Tengah dan Kabupaten Nagan Raya. Kesepuluh: CAT Langsa berada pada lintas provinsi, CAT Langsa dengan luas CAT $853 \mathrm{Km}^{2}$ terdapat pada Kabupaten Aceh Timur, Kota Langsa dan Kabupaten Aceh Tamiang dan Provinsi Sumatera Utara tepatnya di Kabupaten Langkat. Kesebelas: CAT Siongolongol berada pada lintas kabupaten/kota, CAT Siongolongol dengan luas CAT $183 \mathrm{Km}^{2}$ terdapat dalam Kabupaten Gayo Lues dan Kabupaten Aceh Tenggara.

Tabel 1. Potensi air tanah pada CAT di Indonesia

\begin{tabular}{|c|c|c|c|c|c|}
\hline \multirow{2}{*}{ No. } & \multirow{2}{*}{ CAT } & \multirow{2}{*}{ Jumlah } & \multirow{2}{*}{ Luas $\left(\mathrm{Km}^{2}\right)$} & \multicolumn{2}{|c|}{ Potensi air tanah pada akuifer (juta $\mathrm{m}^{3} /$ tahun) } \\
\hline & & & & Bebas & Tertekan \\
\hline 1 & Lintas Negara & 5 & 147.886 & 126.276 & 5.259 \\
\hline 2 & Lintas Provinsi & 36 & 319.635 & 131.186 & 4.127 \\
\hline 3 & Lintas Kabupaten/Kota & 176 & 349.023 & 198.101 & 9.987 \\
\hline 4 & Dalam Kabupaten/Kota & 204 & 91.071 & 40.654 & 1.533 \\
\hline & Total & 421 & 907.615 & 496.217 & 20.906 \\
\hline
\end{tabular}

Sumber: Kodoatie dan Sjarief (2010:132)

Tabel 2. Potensi air tanah pada CAT di Indonesia perpulau

\begin{tabular}{|c|c|c|c|c|c|c|}
\hline \multirow[b]{2}{*}{ No. } & \multirow[b]{2}{*}{ Pulau } & \multirow[b]{2}{*}{ Jumlah CAT } & \multirow[b]{2}{*}{$\begin{array}{l}\text { Luas CAT } \\
\left(\mathrm{Km}^{2}\right)\end{array}$} & \multicolumn{3}{|c|}{ Potensi air tanah pada akuifer } \\
\hline & & & & $\begin{array}{c}\text { Bebas (unconfined) } \\
\left(\mathrm{m}^{3} / \text { tahun }\right)\end{array}$ & $\begin{array}{c}\text { Tertekan (confined) } \\
\left(\mathrm{m}^{3} / \text { tahun }\right)\end{array}$ & $\begin{array}{c}\% \text { tertekan terhadap } \\
\text { bebas }\end{array}$ \\
\hline 1 & Bali & 8 & 4.381 & 1.577 & 21 & $1,3 \%$ \\
\hline 2 & NTB & 9 & 9.475 & 1.908 & 107 & $5,6 \%$ \\
\hline 3 & NTT & 38 & 31.929 & 8.229 & 200 & $2,4 \%$ \\
\hline 4 & Maluku & 68 & 25.830 & 11.943 & 1.231 & $10,3 \%$ \\
\hline 5 & Sulawesi & 91 & 37.778 & 19.694 & 550 & $2,8 \%$ \\
\hline 6 & Jawa \& Madura & 80 & 81.147 & 38.851 & 2.046 & $5,3 \%$ \\
\hline 7 & Kalimantan & 22 & 181.362 & 67.963 & 1.102 & $1,6 \%$ \\
\hline 8 & Sumatera & 65 & 272.843 & 123.528 & 6.551 & $5,3 \%$ \\
\hline 9 & Papua & 40 & 262.870 & 222.524 & 9.098 & $4,1 \%$ \\
\hline & Total & 421 & 907.615 & 496.217 & 20.906 & $4,2 \%$ \\
\hline
\end{tabular}

Sumber: Kodoatie dan Sjarief (2010:132) 


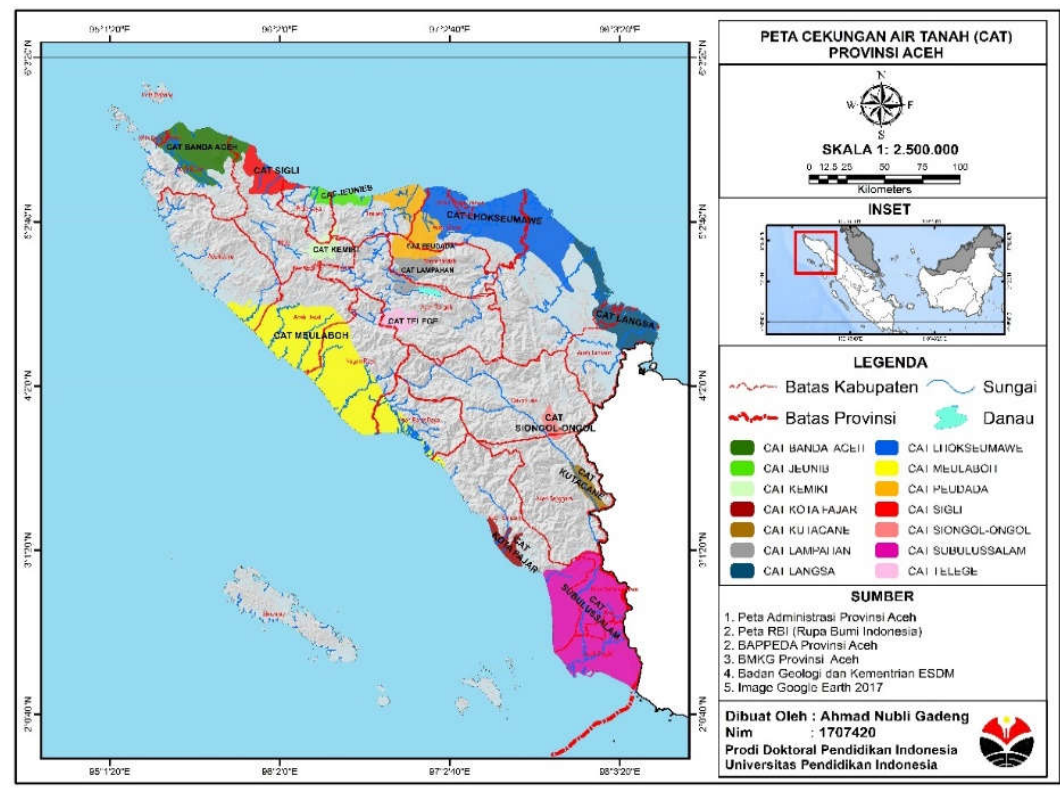

Gambar 3 Peta CAT di Provinsi Aceh

Tabel 3. Keadaan dan Debit Sungai-sungai Besar di Wilayah Kerja BPDAS Krueng Aceh Pengamatan Tahun 2000

\begin{tabular}{|c|c|c|c|c|c|c|c|c|c|c|}
\hline \multirow[b]{2}{*}{ No. } & \multirow[b]{2}{*}{$\begin{array}{c}\text { Propinsi } \\
\text { NAD } \\
\text { Kabupaten/Kota }\end{array}$} & \multirow[b]{2}{*}{$\begin{array}{c}\text { DAS/Sub } \\
\text { DAS }\end{array}$} & \multirow{2}{*}{$\begin{array}{l}\text { Nama- } \\
\text { nama } \\
\text { Sungai } \\
\text { besar }\end{array}$} & \multirow[b]{2}{*}{$\begin{array}{c}\text { Luas Daerah } \\
\text { Tangkapan } \\
\text { Air (Ha) }\end{array}$} & \multirow[b]{2}{*}{$\begin{array}{l}\text { Panjang } \\
\text { Sungai }\end{array}$} & \multicolumn{2}{|c|}{ Nama Lokasi } & \multicolumn{3}{|c|}{ Debit } \\
\hline & & & & & & Hulu & Hilir/Muara & $\begin{array}{l}\text { Rata-rata } \\
\text { M3/detik }\end{array}$ & $\begin{array}{c}\text { Q max } \\
\text { M3/detik }\end{array}$ & $\begin{array}{c}\text { Q min } \\
\text { M3/detik }\end{array}$ \\
\hline 1. & Aceh Besar & Kr. Aceh & Kr. Aceh & 172.37 & 113 & Seulawah & Lampulo & 8.4 & 163 & 6 \\
\hline 2. & Aceh Timur & Jambo Aye & Jambo Aye & 485.955 & 103 & & & 141 & 718.2 & 42 \\
\hline 3. & Pidie & Baro & Baro & 215.226 & 51 & & & 14.2 & 93 & 2.56 \\
\hline 4. & Pidie Jaya & Meureudu & Meureudu & 215,000 & 33 & & & 17.25 & 74 & 3.14 \\
\hline 5. & Aceh Utara & Peusangan & Peusangan & 235.975 & 75 & Takengon & Matang II & 50 & 381.9 & 24.5 \\
\hline \multirow{2}{*}{6.} & \multirow{2}{*}{ Tamiang } & Kr. Tamiang & Kr. Tamiang & 798.895 & 208 & & Tamiang & 124.5 & 150 & 138 \\
\hline & & Peureulak & & & & & & & & \\
\hline \multirow{2}{*}{7.} & \multirow{2}{*}{ Aceh Barat } & Woyla & Kr. Woyla & 513.784 & 125 & & & 3.98 & 968.54 & 3.98 \\
\hline & & Teunom & Kr. Teunom & 130 & 42.91 & & & 1,023 & 15 & 42.91 \\
\hline 8. & Aceh Selatan & Kluet & Kr. Kluet & 612.801 & 80 & Leuser & Kuta Fajar & 248.25 & 448.6 & 47.9 \\
\hline 9. & Aceh Singkil & Kr. Singkil & Kr. Singkil & 120 & & Leuser & Singkil & 51.12 & 146 & 0.31 \\
\hline & Jumlah & & & 218,035 & 1,038 & & & 701.88 & $4,166.39$ & 311.60 \\
\hline
\end{tabular}

Sumber: Statistik Pembangunan Balai Pengelolaan Daerah Aliran Sungai Krueng Aceh Tahun 2008

Keduabelas: CAT Kutacane, berada pada lintas provinsi yaitu antara Provinsi Aceh dan Provinsi Sumatera Utara, dengan luas CAT $351 \mathrm{Km}^{2}$ terdapat pada Kabupaten Aceh Tenggara di Provinsi Aceh dan Kabupaten Karo di Provinsi Sumatera Utara. Ketigabelas: CAT Kotafajar, berada dalam kabupaten/kota saja, CAT Kotafajar dengan luas CAT $351 \mathrm{Km}^{2}$ hanya berada dalam Kabupaten Aceh Selatan saja, dan tidak terhubung dengan kabupaten lainnya yang berada di sekitar Kabupaten Aceh Selatan.

Keempatbelas: CAT Subulussalam berada pada lintas provinsi, yaitu Provinsi Aceh dan Provinsi Sumatera Utara, CAT Subulussalam dengan luas CAT $3632 \mathrm{Km}^{2}$ berada pada Kabupaten Aceh Selatan, Kabupaten Aceh Tenggara, Kota Subulussalam dan Kabupaten Aceh Singkil yang berada pada Provinsi Aceh, dan Kabupaten Tapanuli Tengah di Provinsi Sumatera Utara.

Nah, jadi dengan adanya CAT yang terdapat di Provinsi Aceh, diharapkan dapat memenuhi berbagai kebutuhan air bersih yang dibutuhkan oleh masyarakat Provinsi Aceh pada saat air yang terdapat di permukaan mengalami kekeringan, dan bahkan juga dapat bermanfaat kepada masyarakat yang berada di beberapa kabupaten di Provinsi Sumatera
Utara. CAT yang terluas di Aceh yaitu CAT Meulaboh dengan luas $4500 \mathrm{Km}^{2}$ yang berada pada 4 (empat) kabupaten di pesisir barat Provinsi Aceh yaitu Kabupaten Aceh Jaya, Kabupaten Aceh Barat, Kabupaten Aceh Barat Daya, dan Kabupaten Nagan Raya.

\section{2) Sungai, Wilayah Sungai (WS), Daerah Aliran Sungai (DAS)}

Sungai sebagai salah satu sumber air kehidupan yang berada di permukaan dan memiliki manfaat serta peranan yang sangat penting dalam kehidupan manusia, untuk berbagai kegiatan seperti kebutuhan rumah tangga, kebutuhan industri, kebutuhan pertanian dan berbagai kebutuhan lainnya baik di perdesaan maupun di perkotaan. Dan sungai juga berfungsi sebagai tempat untuk menampung air hujan agar dapat dimanfaatkan kembali oleh manusia. (Soewarno, 1991:20; Kodoatie dan Sugiyanto, 2002: 156) Sungai sebagai torehan yang terdapat di bagian permukaan bumi sebagai tempat penampung dan penyaluran secara alami air dan material-material yang dibawa dari bagian hulu (tempat yang lebih tinggi) ke bagian hilir (tempat yang lebih rendah) dan bermuara atau berakhir ke laut. Bagian sungai untuk 
mendapatkan air atau daerah tangkapan hujan yang dikenal dengan daerah pengaliran sungai (DPS). DPS merupakan unit kesatuan wilayah tempat air hujan menjadi aliran permukaan dan mengumpul ke sungai untuk menjadi aliran sungai. Yang menjadi pembatas antara DPS adalah punggung permukaan bumi yang dapat memisahkan dan membagi air hujan menjadi aliran permukaan ke setiap DPS. DPS besar tersusun atas beberapa DPS sedang/sub DPS, dan sub DPS terdiri atas gabungan dari sub DPS kecil-kecil.

Oleh karena itu, setiap daerah yang menjadi wilayah tangkapan air hujan harus dilindungi ekosistemnya dengan baik, hal ini bertujuan agar sungai tidak mengalami kekeringan pada saat musim kemarau, dan tidak menjadi malapetaka seperti bencana alam banjir bandang dan tanah longsor pada saat musim hujan. Adapun wilayah yang harus dijaga dan dilindungi dengan baik yaitu semua komponenkomponen yang terdapat di sungai, Koadoatie dan Sjarief (2010:231) Komponen utama sungai dapat dibagi menjadi dua yaitu daerah aliran sungai (DAS) dan sistem sungainya. Sistem sungai mempunyai karakteristik yang berbeda baik satu sistem dengan lainnya maupun dalam sistem sungai itu. Dalam satu sistem sungai terdapat perbedaan yaitu kemiringan dasar sungai, penampang sungai, material dan karakteristik lembah sungai.

Kemudian, tidak hanya komponen-komponen sungai saja yang harus dijaga, akan tetapi wilayah atau bagian lainnya di sungai yang harus dijaga dan dilindungi dengan baik mulai dari wilayah hulu sungai, Soewarno (1991:26) Bagian hulu sungai merupakan daerah sumber atau pusat erosi karena pada umumnya alur sungai melalui daerah pegunungan, perbukitan atau lereng gunung api yang kadang-kadang posisinya lebih tinggi dari permukaan laut. Pada saat hujan turun, sebagian dari air akan merembes dan sebagian lagi akan mengalir dengan membawa partikel-partikel tanah sehingga menimbulkan erosi. Alur sungai di bagian hulu ini biasanya mempunyai kecepatan aliran yang lebih besar dari bagian hilir, sehingga pada saat banjir material hasil erosi yang diangkut tidak saja partikel sedimen yang halus akan tetapi juga pasir, kerikil bahkan batu.

Kemudian, bagian sungai kedua yang harus juga dilindungi dan dijaga dengan baik oleh masyarakat adalah bagian tengah sungai. Soewarno (1991:26) Bagian tengah sungai menjadi daerah peralihan dari bagian hulu dan hilir. Pada bagian tengah sungai, kemiringan dasar sungai lebih landai sehingga kecepatan aliran relatif lebih kecil dari pada bagian hulu sungai. Pada saat alur sungai datang dari daerah pegunungan secara mendadak dan selanjutnya memasuki daerah dataran, biasanya sedimen diendapkan pada bagian daerah yang mengalami perubahan kemiringan lereng dasar sungai. Bentuk endapan yang terjadi pada bagian tengah sungai melebar ke arah hulu dengan material yang kasar terdapat di bagian hulu dan secara bertahap semakin halus ke arah bagian hilir sungai, bentuk demikian yang sering dikenal dengan kipas aluvial.

Dan yang terakhir, bagian sungai yang harus dijaga dan dilindungi dengan baik oleh masyarakat adalah bagian hilir sungai. Soewarno (1991:26) Bagian hilir sungai biasanya melalui daerah pendataran (dataran) yang terbentuk dari endapan pasir halus sampai kasar, lumpur, endapan organik dan jenis endapannya lainnya yang sifatnya sangat labil. Alur sungai yang berbelok-belok disebut dengan meander. Bentuk alur demikian banyak dijumpai di daerah pedataran (dataran) sebelah timur Pulau Sumatera. Endapan yang terbentuk tersebut pada umumnya mempunyai sifat lembek sehingga dengan demikian sifat endapannya harus benar-benar diperhitungkan apabila pada lokasi itu ingin direncanakan bangunan pos duga air.

Oleh karena itu, apabila menginginkan keadaan sungai akan selalu bersih dan jumlah debit akan tetap stabil meskipun dalam musim kemarau, dan juga untuk menghindari terjadinya bencana alam seperti banjir, banjir bandang dan tanah longsor, membutuhkan peran masyarakat dan pemerintah untuk menjaga dan melindungi semua bagian sungai mulai dari bagian hulu sungai, bagian tengah sungai dan bahkan sampai bagian hilir sungai. Hal ini dikarenakan sangat banyak faktor yang mempengaruhi sungai menjadi rusak dan tercemar, Koadoatie dan Sjarief (2010:231) Banyak faktor dan variabel yang mempengaruhi secara langsung yaitu: debit, kemiringan memanjang, muatan sedimen, perlawanan aliran (resistance to flow) baik di tebing maupun dasar sungai, vegetasi, temperatur, geologi dan aktifitas manusia.

Tidak ada manfaat dan sia-sia saja jikalau yang dijaga dan dilindungi cuma bagian hilir dan bagian tengah saja, akan tetapi bagian hulu sungai tidak dijaga dan dilindungi dengan baik oleh pemerintah dan masyarakat. Koadoatie dan Sjarief (2010:231) Berbagai aktifitas yang terjadi baik itu yang berasal dari alam maupun yang disebabkan oleh manusia dapat mempengaruhi kondisi permukaan sungai dan sekitarnya, sehingga diharapkan kepada manusia agar dapat menjaga kebersihan dan kelestarian lingkungan di sekitar sungai. Perlu diketahui bersama yaitu, sungai memiliki fungsi dan manfaat yang sangat besar untuk kehidupan masyarakat. Soewarno (1991:20) Dari sudut pandang hidrologi, sungai mempunyai fungsi utama yaitu menampung curah hujan dan mengalirkan air sampai ke laut. Kemudian, Koadoatie dan Sjarief (2010:231) Fungsi utama sungai adalah sebagai pembawa air dan sedimen.

Di Provinsi Aceh terdapat 10 sungai yaitu, Sungai Geumpang, Sungai Kruet, Sungai Meureudue, Sungai Peureulak, Sungai Peusangan, Sungai Ranggos, Sungai Simpang Kanan, Sungai Simpang Kiri, Sungai Teunom, Sungai Waila. Sungai-sungai tersebut tersebar di seluruh Provinsi Aceh, baik di bagian timur, tengah dan barat selatan Provinsi Aceh. Diantara sungaisungai tersebut ada yang melintasi dalam kabupaten, antar kabupaten dan bahkan ada juga yang antar 
provinsi yaitu, Provinsi Aceh dan Provinsi Sumatera Utara.

Kemudian, berdasarkan Permen PU No.11A/PRT/M/2006 tentang kriteria dan penetapan wilayah sungai dan Renstra SDA Prov Aceh 20072012, di Provinsi Aceh terdapat 11 wilayah sungai (WS), wilayah sungai (WS) adalah kesatuan wilayah pengelolaan SDA dalam satu atau lebih DAS dan atau pulau-pulau kecil yang luasnya kurang dari atau sama dengan $2.000 \mathrm{Km}^{2}$. Satu wilayah sungai terdiri atas beberapa DAS. (UU No.7 tahun 2004 tentang sumber daya air). Wilayah sungai (WS) di Provinsi Aceh ada yang lintas provinsi, lintas kabupaten/kota, dan dalam kabupaten/kota. Dalam pengelolaan wilayah sungai (WS) di provinsi Aceh ada yang dikelola oleh Pemerintah Pusat, pemerintah provinsi dan pemerintah kabupaten/kota.

Adapun sebelas wilayah sungai yang terdapat di Provinsi Aceh yaitu, wilayah sungai Alas Singkil berstatus lintas provinsi, karena berada diantara Provinsi Aceh dan Provinsi Sumatera Utara dan memiliki DAS Lae Pardomuan, Lae Silabuhan, Lae Saragian, Lae Singki, L.Kuala Baru; Wilayah sungai Meureudu-Baro berstatus strategis nasional pada posisi lintas kabupaten, dan memiliki DAS Meureudu, Baro, Tiro, Pante Raja, Utue, Putu, Trienggadeng, Pangwa, Beuracan, Batee; Wilayah sungai Jamboe Aye berstatus strategis nasional pada posisi lintas kabupaten, dan memiliki DAS Jambo Aye, Geuruntang, Reungget, Lueng, Simpang Ulim, Malehan, Julok Rayeuk, Keumuning, Ganding Idi Rayeuk, Lancang, Jeungki, Peundawa Rayeuk, Peureulak, Peundawa Puntong, Leugo Rayeuk;

Wilayah sungai Woyla-Seunagan berstatus strategis nasional pada posisi lintas kabupaten, dan memiliki DAS Woyla-seunagan; Wilayah sungai TripaBateutue berstatus strategis nasional pada posisi lintas kabupaten, dan memiliki DAS Tripa-Bateutue; Wilayah sungai Krueng Aceh pada posisi lintas kabupaten, dan memiliki DAS Aceh, Raya, Teungku, Batee; Wilayah sungai Pase-Peusangan pada posisi lintas kabupaten, dan memiliki DAS Pase, Peusangan, Peudada, Keureuto, Mane, Geukeuh; Wilayah sungai Tamiang-Langsa pada posisi lintas kabupaten, dan memiliki DAS Tamiang, Langsa, Raya, Telaga Muku, Bayeuen; Wilayah sungai Teunom-Lambeusoi pada posisi lintas kabupaten, dan memiliki DAS Teunom, Lambeusoi, Bubon, Sabe, Masen, Inong; Wilayah sungai Krueng Baru-Kluet pada posisi lintas kabupaten, dan memiliki DAS Krueng Baru-Kluet; Wilayah sungai Pulau Simeulue pada posisi dalam kabupaten, dan memiliki DAS sungai-sungai di Pulau Simeulue.

Selanjutnya, akan dibahas tentang DAS, daerah aliran sungai adalah suatu wilayah daratan yang merupakan satu kesatuan dengan sungai dan anakanak sungai, yang berfungsi menampung, menyimpan, dan mengalirkan air yang berasal dari air hujan ke danau atau ke laut secara alami, yang batas di darat merupakan pemisah topografis dan batas di laut sampai dengan daerah perairan yang masih terpengaruhi aktivitas daratan (UU nomor 37 tahun 2012 tentang pengelolaan daerah aliran sungai pasal 1). DAS secara umum didefinisikan sebagai suatu hamparan wilayah/kawasan yang terbentuk secara alamiah, dibatasi oleh pembatas topografi (punggung bukit) yang menerima, mengumpulkan air hujan, sedimen dan unsur hara serta mengalirkannya melalui anak-anak sungai yang terletak di dalam wilayah DAS tersebut dan keluar pada sungai utama ke laut atau danau (Effendi, 2008:2; Kodoatie dan Sjarief, 2008:16).

DAS dapat diartikan sebagai kesatuan ruang yang terdiri atas unsur abiotik (tanah, air, udara), biotik (vegetasi, binatang dan organisme hidup lainnya) dan kegiatan manusia yang saling berinteraksi dan saling ketergantungan satu sama lain, sehingga merupakan satu kesatuan ekosistem, hal ini berarti bahwa apabila keterkaitan sudah terselenggara maka pengelolaan hutan, tanah, air, masyarakat dan lain-lain harus memperhatikan peranan dari komponen-komponen ekosistem tersebut. (Notohadiprawiro,1985; Martopo, 1994; Soemarwoto, 1985, Sudaryono, 2002:153; Setyowati dan Suharini, 2014: 34). Tujuan dari pengelolaan DAS pada dasarnya adalah pemanfaatan sumberdaya alam dilakukan dengan terlanjutkan (sustainable) sehingga tidak membahayakan lingkungan lokal, regional, nasional dan bahkan global. (Sudaryono, 2002:155). Fungsi DAS yaitu untuk fungsi konservasi, fungsi pemanfaatan air sungai untuk kepentingan sosial dan ekonomi (Effendi, 2008: 3).

Di Provinsi Aceh terdapat 15 daerah aliran sungai (DAS), adapun DAS yang terdapat di Provinsi Aceh yaitu: DAS Pulau Weh, DAS Jambo Aye, DAS Kluet, DAS Krueng Aceh, DAS Krueng Baro, DAS Merbau, DAS Meureudu, DAS Pase, DAS Peureulak/Tamiang, DAS Peusangan, DAS Sabe Geupe, DAS Simeulue, DAS Singkil, DAS Teunom Woyla, DAS Tripe Batee. Untuk lebih jelasnya tentang keadaan dan debit sungai yang terdapat di Provinsi Aceh, silahkan dilihat pada tabel 3.

Kemudian, DAS yang memiliki luas dan rata-rata debit yang cukup besar terdapat di Provinsi Aceh yaitu, sebagai berikut: DAS Kr. Aceh dengan debit ratarata $19,10 \mathrm{M}^{3} /$ detik dengan luas $1.780 \mathrm{Km}^{2}$ dan bermuara ke Selat Malaka, DAS Kr. Pase dengan debit rata-rata 91,12 $\mathrm{M}^{3} /$ detik dengan luas $2.272 \mathrm{Km}^{2}$ dan bermuara ke Selat Malaka, DAS Kr. Peusangan dengan debit rata-rata $88,90 \mathrm{M}^{3}$ /detik dengan luas $1.907,95$ $\mathrm{Km}^{2}$ dan bermuara ke Selat Malaka, DAS Kr. Peudada dengan debit rata-rata $21,98 \mathrm{M}^{3}$ /detik dengan luas $1.560 \mathrm{Km}^{2}$ dan bermuara ke Selat Malaka, DAS Kr. Tamiang dengan debit rata-rata 296,64 $\mathrm{M}^{3} /$ detik dengan luas 4.683,60 $\mathrm{Km}^{2}$ dan bermuara ke Selat Malaka, DAS Kr. Teunom dengan debit rata-rata 192,91 $\mathrm{M}^{3} /$ detik dengan luas $2.413 \mathrm{Km}^{2}$ dan bermuara ke Samudera Hindia dan DAS Kr. Kluet dengan debit rata-rata 248,25 $\mathrm{M}^{3}$ /detik dengan luas $2.326 \mathrm{Km}^{2}$. 


\section{3) Danau}

Di Provinsi Aceh terdapat 7 danau dan tersebar di beberapa kabupaten/kota yang terdapat di Provinsi Aceh. (Lintas Gayo.co.id dan Pusdata Kementrian PU 2015) Adapun danau-danau yang terdapat di Provinsi Aceh yaitu: Danau Laut tawar merupakan salah danau terbesar di Provinsi Aceh dan terletak di Aceh Tengah, Danau Laut Tawar memiliki luas 5.761 hektar dengan volume 175 juta $\mathrm{M}^{3}$ air dan daerah tangkapan 110,00 $\mathrm{Km}^{2}$, dan menjadi sumber kehidupan untuk masyarakat yang berada di Takengon, yang terkenal sebagai penghasil kopi terbaik di Provinsi Aceh dan bahkan di Indonesia.

Danau Bungara terletak di Kota Baharu, tepatnya di Kabupaten Aceh Singkil dengan ibukotanya Singkil dan menjadi danau terbesar kedua di Provinsi Aceh. Danau Bungara memiliki luas 85,65 hektar dengan volume danau mencapai $1.446 .375 \mathrm{M}^{3}$ dan daerah tangkapan tidak ditemui data yang akurat. Danau Bungara memiliki 3 pulau kecil yang berada di sekelilingnya dan menambah lengkapnya keindahan alam yang terdapat di Danau Bungara, dikelilingi oleh 4 perkampungan yang berada di sekitar Danau Bungara. Danau Laut Bangko terletak di Kabupaten Aceh Selatan dengan ibukotanya Tapaktuan dan menjadi danau terbesar ketiga di Provinsi Aceh, Danau Laut Bangko memiliki luas 70,8 hektar dan volume air mencapai 2,4 juta $\mathrm{M}^{3}$ dan daerah tangkapan 4,80 $\mathrm{Km}^{2}$. Danau Paris terletak di Kabupaten Aceh Singkil, menjadi danau terbesar keempat di Provinsi Aceh, Danau Paris memiliki luas 58,51 hektar dan volume 877,650 $\mathrm{M}^{3}$ dan daerah tangkapan tidak ditemui data yang akurat.

Danau Aneuk laot terletak di Kota Sabang, dan menjadi sumber kehidupan masyarakat yang berada di Kota Sabang yang terkenal dengan keidahan alamnya. Danau Aneuk laot menjadi danau terbesar kelima di Provinsi Aceh, Danau Aneuk laot memiliki luas 45,9 hektar dan volume 3 juta $\mathrm{M}^{3}$ dan daerah tangkapan 5,30 $\mathrm{Km}^{2}$. Danau Pinang terletak di Kabupaten Aceh Singkil dan memiliki luas 34,45 hektar dengan volume $516.750 \mathrm{M}^{3}$ dan daerah tangkapan $4,20 \mathrm{Km}^{2}$. Kemudian, yang terakhir yaitu Danau Pinang merupakan danau kedua terkecil di Aceh setelah Danau Peastep yang terletak di Kabupaten Gayo Lues. Danau Peastep Gayo lues menjadi danau terkecil di yang terdapat di Provinsi Aceh, dan memiliki luas 10,9 hektar, dengan volume air mencapai 2 juta $\mathrm{M}^{3}$ dan daerah tangkapan 3,50 $\mathrm{Km}^{2}$, dengan volume tersebut termasuk dalam kategori banyak untuk menampung air yang berada di dalam danau Peastep.

\section{Kesimpulan}

Tipologi sumber daya air yang terdapat di Provinsi Aceh dengan ketersediaan air yang sangat melimpah, seperti yang terdapat di cekungan air tanah (CAT) berjumlah 14 buah, 10 sungai, 11 wilayah sungai (WS), 15 daerah aliran sungai (DAS) dan 7 danau yang tersebar di seluruh Provinsi Aceh. Kemudian, pemanfaatan air dalam masyarakat Aceh digunakan untuk berbagai keperluan masyarakat, seperti MCK (mandi, cuci, kakus), keperluan ibadah, keperluan pertanian, perkebunan, peternakan, perindustrian,

Adapun saran yang diberikan dalam artikel ini yaitu diharapkan kepada pemerintah dan masyarakat Provinsi Aceh agar dapat menghemat penggunaan air, tidak digunakan secara boros dan berlebihan, dan menjaga dengan baik lingkungan ekosistem sungai dan danau agar tidak rusak, tidak tercemar dan tidak mengalami kekeringan pada saat musim kemarau.

Hal tersebut dilakukan agar anak cucu kita di masa mendatang dapat menikmati air yang melimpah juga sebagaimana yang kita nikmati saat ini merupakan warisan dari nenek moyang sebelumnya. Karena dikhawatirkan apabila penggunaan air saat ini secara berlebihan, sembarangan atau tidak dijaga kebersihannya, maka akan berdampak terhadap kekurangan atau defisit air dan air juga sungai akan tercemar, sehingga akan berakibat air sungai tidak layak untuk dikonsumsi oleh masyarakat di masa yang akan datang pada anak cucu kita nantinya.

\section{UCAPAN TERIMA KASIH}

Ucapan terima kasih kepada dosen pembimbing mata kuliah analisis konten hidrosfer dan kehidupan manusia Prof. Dr. Ir. H. Dede Rohmat, M.T. Ayahanda Dr. Ramli Gadeng, M. Pd. Ibunda Yusnidar, Saudari Nana Risna, S.Pd, Saudara Muhammad Reza yang sudah membantu penulis dalam rangka menyelesaikan artikel ini.

\section{DAFTAR PUSTAKA}

Agustiningsih, Dyah. Sasongko, Budi Setia, dan Sudarno. 2012. Analisis Kualitas Air Dan Strategi Pengendalian Pencemaran Air Sungai Blukar Kabupaten Kendal Jurnal PRESIPITASI Vol. 9 No.2 September 2012, ISSN 1907-187X.

Balai Pengelolaan Daerah Aliran Sungai Krueng Aceh. 2009. Statistik Pembangunan Balai Pengelolaan Daerah Aliran Sungai Krueng Aceh Tahun 2008. Banda Aceh: Departemen Kehutanan Direktorat Jenderal Rehabilitasi Lahan Dan Perhutanan Sosial.

Effendi, Edie. 2008. Kajian Model Pengelolaan Daerah Aliran Sungai (Das) Terpadu. Direktorat Kehutanan Dan Konservasi Sumberdaya Air.

Gregory, K.J. and Walling, D.E. 1973. Drainage Basin Form and Process. Fletcher and Son Ltd. Norwich.

Jusuf, saputra Andri. 2015. Geologi Dan Pemetaan Cekungan Air Tanah Kota Gorontalo Dengan Menggunakan Metode Geolistrik Tahanan Jenis. Jurnal Fakultas MIPA, UNG.

Kementerian PUPR. 2015. Peraturan Menteri Pekerjaan Umum Dan Perumahan Rakyat Nomor 04/PRT/M/2015 Tentang Kriteria Dan Penetapan Wilayah Sungai.

Kodoatie, Robert J dan Sjarief, Rosetam. 2008. Pengelolaan Sumber Daya Air Terpadu. Yogyakarta: Andi

Kodoatie, Robert J dan Sjarief, Rosetam. 2010. Tata Ruang Air: Pengelolaan bencana, pengelolaan infrastruktur, penataan ruang wilayah, pengelolaan lingkungan hidup. Yogyakarta: Andi. 
Kodoatie, Robert J dan Sugiyanto. 2002. Banjir- Beberapa penyebab dan metode pengendaliannya dalam perspektif Lingkungan. Yogyakarta: Pustaka Pelajar.

Kodoatie, Robert J. 2012. Tata Ruang Air Tanah. Yogyakarta: Andi.

Lintas Gayo, Media Online. 2014. Ini dia data 7 danau di Provinsi Aceh, Laut Tawar paling besar. http://lintasgayo.co/2014/06/17/ini-dia-data-7danau-di-provinsi-aceh-laut-tawar-paling-besar.

Martopo, S. dkk. 1994. Dasar-dasar Ekologi. Program Pasca Sarjana Universitas Gadjah Mada, Yogyakarta

Notohadiprawiro T., 1988. Tanah, Tataguna Lahan dan Tata Ruang dalam Aanalisis Dampak Lingkungan. PPLHUGM, Yogyakarta.

Peraturan Pemerintah No. 43 tahun 2008 Tentang Air Tanah.

Pusat Lingkungan Geologi, Badan Geologi, Dep. ESDM. 2009. Peta CAT Indonesia. Lampiran KepPres tentang Penetapan CAT Indonesia, Juni.

Renstra SDA Prov Aceh 2007-2012.

Seizarwati, Wulan. Dan Rengganis, Heni. 2016. Tipologi Dan Kualitas Sumber-Sumber Air Di Pulau Yamdena Dan
Selaru, Maluku Tenggara Barat. Jurnal Sumber Daya Air Vol.12 No. 1, Mei 2016: 77 - 88.

Setyowati, Liesnoor Dewi dan Suharini, Erni. Das Garang Hulu: Tata Air, Erosi dan Konservasi. Yogyakarta: Ombak.

Soemarwoto, Otto. 1985. Ekologi, Lingkungan Hidup dan Pembangunan. Penerbit Jambatan, Jakarta.

Soewarno. 1991. Hidrologi Pengukuran dan Pengolahan Data Aliran Sungai (Hidrometri). Bandung: Nova.

Sudaryono, 2002. Pengelolaan Daerah Aliran Sungai (Das) Terpadu, Konsep Pembangunan Berkelanjutan. Jurnal Teknologi Lingkungan, Vol.3, No. 2, Mei 2002: 153-158.

Suriawiria, Unus. 2003. Air dalam Kehidupan dan Lingkungan yang Sehat. Penerbit Alumni. Bandung.

Todd, D.K, 1980. Groundwater Hydrology. John Wiley \& Sons, New York.

UU No.7 tahun 2004 Tentang Sumber Daya Air.

Wiwoho, 2005, Model Identifikasi Daya Tampung Beban Cemaran Sungai Dengan QUAL2E. Tesis. Universitas Diponegoro. Semarang.

Younger, Paul. L. 2007. Groundwater in the Environment. Blackwell Publishing Ltd, Victoria 3053 Australia. 